\title{
STRATEGI PENGEMBANGAN PERUSAHAAN PERDAGANGAN EMAS WILAYAH JABODETA (STUDI KASUS PT XYZ)
}

\section{DEVELOPMENT STRATEGY OF GOLD TRADE COMPANY JABODETA AREA (CASE STUDY OF PT XYZ)}

\section{Primasti Ramadhani*), Lukman M Baga**), dan Bunasor Sanim***)}

\author{
*) Graha Mandiri
}

Jl. Imam Bonjol No.61, RT.8/RW.4, Menteng, Kota Jakarta Pusat, Daerah Khusus Ibukota Jakarta 10310

${ }^{* *}$ Departemen Agribisnis, Fakultas Ekonomi dan Manajemen, Institut Pertanian Bogor

Jl. Kamper Wing 4 Level 5 Kampus IPB, Bogor 16680

${ }^{* * *}$ Sekolah Bisnis, Institut Pertanian Bogor

Jl. Raya Pajajaran, Bogor 16153

\begin{abstract}
Gold has been tested for a long time, in addition to being a high-value precious metal that is used in various industries, fields of medicine, electronics and as a currency. This research is related to the decrease in turnover of PT XYZ amid business competition in the field of gold trading business. The purpose of this study, namely to identify the PT XYZ business model in the Jabodeta area, was reviewed using the current canvas business model approach; evaluating 9 elements of PT XYZ's business using BMC; and formulating competitive strategies through change factors using the right business model for the company. The analysis used is using SWOT analysis, Business Model Canvas (BMC) and Blue Ocean Strategy (BOS). The results of the study show that there is innovation competition from competitors, high turnover sales and less targeted marketing strategies make a decrease in income from its superior products in the form of pawning and gold purchases in installments. In observations of SWOT Analysis The company produces a business model of improvement, there are several elements such as key activities, cost structure and key Resources in the canvas business model that need to be re-examined so that the company can compete with competitors. Blue ocean strategy produces new opportunities for PT XYZ by becoming a bailout provider for customers to make purchases at gold shops who has partnered with PT XYZ.
\end{abstract}

Keywords: gold trading company, bmc, swot analysis, blue ocean strategy, gold

\begin{abstract}
Abstrak: Emas telah teruji ketangguhannya sejak lama, selain sebagai logam mulia bernilai tinggi yang digunakan pada berbagai industri, bidang kedokteran, elektronik dan sebagai mata uang. Penelitian ini terkait dengan penurunan omset PT XYZ ditengah persaingan bisnis dibidang usaha perdagangan emas. Tujuan penelitian ini, yaitu mengidentifikasi model bisnis PT XYZ wilayah Jabodeta, ditinjau menggunakan pendekatan model bisnis kanvas saat ini; mengevaluasi 9 elemen bisnis PT XYZ menggunakan BMC; dan membuat formulasi strategi bersaing melalui faktor perubahan menggunakan model bisnis yang tepat bagi perusahaan. Analisis yang digunakan yaitu menggunakan analisis SWOT, Business Model Canvas (BMC) dan Blue Ocean Strategy (BOS). Hasil penelitian menunjukan adanya persaingan inovasi dari kompetitor, tingginya turn over sales serta strategi pemasaran yang kurang tepat sasaran membuat adanya penurunan pendapatan dari produk unggulannya berupa gadai dan pembelian emas secara cicilan.Hasil pengamatan Analisis SWOT perusahaan menghasilkan model bisnis perbaikan, terdapat beberapa eleman seperti key activities, cost strurcture dan key Resources dalam model bisnis kanvas yang perlu dilakukan pengkajian kembali agar perusahaan dapat bersaing dengan kompetitor. Blue ocean strategy menghasilkan peluang baru bagi PT XYZ dengan menjadi penyedia dana talangan bagi nasabah untuk melakukan pembelian di toko emas yang telah bermitra dengan PT XYZ.
\end{abstract}

Kata kunci: perusahaan perdagangan emas, BMC, analisis SWOT, blue ocean strategi, emas

\footnotetext{
${ }^{1}$ Alamat Korespondensi:

Email: asti.ramadhani@gmail.com
} 


\section{PENDAHULUAN}

Fluktuasi harga emas yang kurang stabil dalam kurun waktu 2011-2015 tidak menyurutkan minat masyarakat untuk melakukan pembelian emas (Gambar 1). Hal ini menyebabkan banyak perusahaan berlomba menyediakan layanan kepemilikan emas termasuk didalamnya pemain besar seperti Pegadaian dan Bank Syariah yang menyediakan layanan pembelian emas. Persaingan yang tinggi ini menuntut perusahaan memberikan pelayanan terbaik.

Tingkat konsumsi manyarakat Indonesia terhadap emas terbilang memiliki potensi yang luar biasa. Hal ini didukung oleh jumlah penduduknya yang mencapai 251 juta orang, dimana sekitar 51,11\% merupakan pekerja (BPS, 2015). Namun, belanja emas sebagai tabungan maupun alat investasi tidak sebanding dengan belanja alat elektronik maupun kendaraan bermotor, padahal Indonesia merupakan salah satu negara penghasil emas terbesar. Di tahun 2010, konsumsi emas Indonesia adalah 36.4 ton, angka ini menyusut lebih dari 50\% jika dibandingkan dengan kondisi di tahun 2003, yakni 83,6 ton.

PT XYZ menyediakan layanan penjualan emas dengan menyediakan opsi pembelian kembali setelah tenor yang disepakati. PT XYZ telah memposisiskan dirinya sebagai perusahaan yang salah satunya menyasar sektor masyarakat menengah dan menengah kebawah. Hal ini ditandai dengan pencapaian omset sebesar 60 milyar rupiah di tahun 2013, 200 milyar di tahun 2014 dan 300 milyar di akhir tahun 2015 (Laporan Marketing, 2015). Namun, kondisi bisnis PT XYZ saat ini mengalami penurunan terutama jumlah transaksi untuk beberapa produk utamanya seperti gadai cicilan dan pembelian emas cicilan. Sementara perusahaan memiliki rencana untuk mengembangkan bisnisnya melalui penambahan cabang di beberapa wilayah di Jabodeta dan sekitarnya. Selain itu, peluang perdagangan emas yang besar membuat perusahaan yang menyediakan jasa perdagangan emas pun bermunculan. Selain Pegadaian yang sebelumnya fokus pada bidang gadai, Bank Syariah, pegadaian swasta, dan toko mas konvensional kini bersaing memberikan fasilitas terbaik untuk memenuhi kepuasan pelanggan. Hal ini membuat PT XYZ perlu untuk mengmbangkan diri agar dapat bersaing dengan perusahaan sejenis

Model bisnis kanvas adalah suatu kerangka model bisnis yang berbentuk kanvas yang terdiri dari 9 kotak yang berkaitan. Menurut (Eppler, 2011) pemanfaatan template visual, Objek, dan sketsa dapat meningkatkan kualitas komunikasi dalam penyampaian ide dan meningkatkan kreatifitas individu dalam sebuah tim. Kotak-kotak tersebut merupakan pengembangan dari dari empat bidang utama dalam suatu bisnis yaitu pelanggan, penawaran, infrastruktur dan kelangsungan finansial. Konsep ini menjadi bahasa bersama yang memudahkan dalam menggambarkan dan memanipulasi bisnis untuk menciptakan alternatif strategi baru melalui analisis lingkungan (eksternalinternal), formulasi strategik, implementasi strategik, serta evaluasi dan kontrol (Wheelen dan Hunger, 2010). Tanpa adanya pemahaman bersama, sulit bagi perusahaan untuk secara sistematis meningkatkan kinerjanya dan berhasil dalam berinovasi. Model bisnis selain itu dapat mempercepat pengembangan konsep, proses penilaian, dan meningkatkan kualitas bisnis yang diteruskan ke tahap perencanaan bisnis (Leschke, 2013).

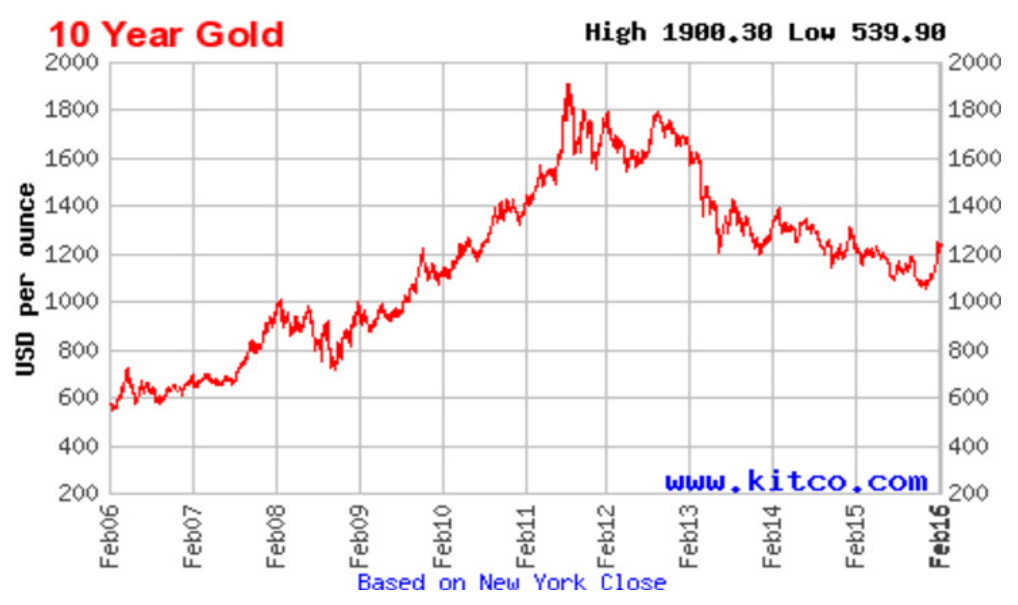

Gambar 1. Fluktuasi harga emas tahun 2006-2015 
Terdapat beberapa kajian yang menjadi acuan dalam penelitian ini. Pertama penelitian Destiani (2014), mengenai perbaikan kondisi bandara menggunakan penerapan sembilan elemen dalam bisnis model kanvas. Hasil penelitian ini menunjukkan bahwa manajemen perusahaan perlu melakukan formulasi strategi kepada tiga elemen, yaitu key activities, key resources, dan channel. Tiga elemen tersebut dipilih karena memiliki pengaruh besar terhadap pengembangan bandara serta terhadap elemen lainnya. Sementara itu, enam elemen lainnya dianggap masih relevan. Kedua Ghaffari (2014), melakukan pengembangan model bisnis kafe momomilk Bogor. Dengan melakukan ideentifikasi model bisnis melalui wawancara dengan pemilik kafe, identifikasi faktor internal dengan identifikasi produk, customer interface, infrastructure management, dan financial aspect. Analisis faktor eksternal melalui PEST, five force porter, dan persepsi pelanggan. Kemudian melalui identifikasi tersebut penulus memetakan menggunakan analisis SWOT untuk kemudian diterapkan dalam perumusan dalam BMC. Ketiga Marahakim (2012), dalam jurnalnya menggunakan kanvas model bisnis untuk mencari tahu kendala yang dihadapi oleh perusahaan. Terutama terkait rendahnya nominal penjualan majalah yang telah berdiri selama 3 tahun. Dari penerapan model ini diperoleh aspekaspek yang memerlukan perhatian khusus untuk dirubah dan dikembangkan. Aspek tersebut antara lain customer segment, customer relationship, distribution channel, key activities dan key partner. Penelitian ini menggunakan metode pengumpulan data dari hasil observasi, interview dan forum group discussion dengan pakar.

Perusahaan berencana mengembangkan bisnisnya melalui penambahan cabang di beberapa wilayah di Jabodeta dan penambahan area baru di Indonesia bagian tengah. Oleh karena itu, tujuan dalam penelitian ini, yaitu mengidentifikasi model bisnis PT XYZ wilayah Jabodeta, ditinjau menggunakan pendekatan model bisnis kanvas saat ini; mengevaluasi 9 elemen bisnis PT XYZ menggunakan BMC; dan membuat formulasi strategibersaingmelalui faktor perubahan menggunakan model bisnis yang tepat bagi perusahaan.

\section{METODE}

Penelitan dilakukan di lingkungan PT XYZ wilayah Jakarta, Bogor dan Tangerang (Jabodeta). Adapun penelitian dilakukan pada bulan Maret hingga Agustus
2016. Kriteria pemilihan PT XYZ wilayah Jabodeta dilakukan secara sengaja berdasarkan pertimbangan ketersediaan data dan kesediaan manajemen perusahaan untuk dilakukan penelitian.Penelitian dilakukan di wilayah Jabodeta dikarenakan jangkauan dalam memperoleh data internal dan karakteristik pelanggan yang berbeda dibandingkan area wilayah lain, dimana karakeristik nasabah yang berada di area Jawa Barat yang umumya melakukan gadai perhiasan dan berlian, sementara nasabah di area Jawa Timur lebih banyak melakukan gadai perhiasan emas tua, nasabah area makassar lebih banyak melakukan gadai dan karakteristik nasabah yang berada di area Jabodeta lebih cenderung melakukan transaksi pembelian emas. Kemudahan menjangkau setiap cabang dalam satu area dan komunikasi yang baik antara penulis dan sumber data area Jabodeta dibandingkan dengan area lain menjadi rujukan penulis dalam pemilihan area penelitan.

Pendekatan penelitian yang digunakan dalam penelitian ini adalah metode deskriptif melalui studi kasus. Penggunaan studi kasus dilakukan dengan tujuan memperoleh gambaran dan informasi yang lebih rinci mengenai suatu objek tertentu selama kurun waktu tertentu dengan cukup mendalam dan menyeluruh, termasuk lingkungan internal dan ekstrenal yang mempengaruhinya (Nazir, 1999). Metode ini menggambarkan fakta dan populasi dari suatu permasalahan tertentu pada suatu perusahaan atau organisasi atau lingkungan secara faktual dan sistematis. Metode ini memberikan data dan fakta yang berkaitan dengan objek penelitian yang dihimpun guna mendapatkan gambaran dan informasi yang lebih mendalam selama periode tertentu.

Metode penentuan responden, penentuan responden dilakukan dengan menggunakan teknik purposive sampling (dipilih dengan sengaja) yang digunakan untuk menentukan responden yang menjadi individual in-depth interview. Teknik Penetapan responden menggunakan sampling purposive. Jumlah responden yang dipilih disesuaikan dengan kebutuhan penulis dalam pengumpulan data. Melalui pendekatan yang sederhana, manajer dan karyawan dapat meningkatkan persepsi dan pemahaman mengenai kondisi perusahaan saat ini. Hal in membuat karyaan lebih leluasa memberikan ide dan saran kepada perusahaan (Graviola et al. 2014). Responden Penelitian dari pihak internal dan eksternal PT XYZ pada Tabel 1. 
Tabel 1. Responden penelitian dari pihak internal dan eksternal PT XYZ

\begin{tabular}{lc}
\hline \multicolumn{1}{c}{ Daftar responden } & Jumlah \\
\hline Area Manajer & 2 Orang \\
Area Sales Manajer & 1 Orang \\
Branch Manajer & 5 Orang \\
Auditor & 1 Orang \\
Nasabah & 30 Orang \\
\hline
\end{tabular}

Metodepenelitian yang akan digunakan dalampenelitian ini adalah analisis kualitatif dan kuantitatif dengan pendekatan studi kasus. Penelitian ini menggunakan data primer dan sekunder, dengan teknik pengumpulan data melalui wawancara, studi pustaka, observasi, dan kuesioner.

Analisis data yang digunakan dalam penelitian ini menggunakan beberapa pola analisis, yaitu analisis deskriptif, model bisnis kanvas awal, analisis SWOT tiap elemen model bisnis, model bisnis kanvas perbaikan, blue ocean strategy (BOS), dan model bisnis alternatif. Kerangka pemikiran penelitian selengkapnya pada Gambar 2.

\section{HASIL}

\section{Identifikasi Elemen-Elemen Model Bisnis}

Perumusan bisnis model kanvas PT XYZ didahului dengan melakukan identifikasi struktur bisnis kesembilan elemen bisnis model kanvas mengenai kondisi perusahaan saat ini. Hasil perumusan ini diperoleh melalui kegiatan observasi, wawancara dan penyebaran kuesioner yang dilakukan dengan internal dan eksternal perusahaan. Hasil kegiatan tersebut dihasilkan gambaran model pengelolaan bisnis yang berkaitan satu sama lain mengenai keadaan perusahaan saat ini secara lebih terperinci. Identifikasi model bisnis perusahaan saat ini bermanfaat untuk mengetahui baik kondisi internal maupun eksternal perusahaan. Banyaknya perusahaan yang bergerak dalam bisnis serupa membuat PT XYZ perlu memahami kondisai perusahaan awal sebagai bekal untuk merancang model bisnis perbaikan.Berdasarkan model bisnis PT XY saat ini, dapat di identifikasikan elemen model bisnis kanvas seperti pada Gambar 3.
Pada pengembangan model bisnis ini penulis mencoba menggunakan penjabaran Ostelwalder dan Pigneur (2012) menggunakan perspektif model bisnis dengan BOS yang memberikan gambaran besar secara visual yang membantu untuk melihat dampak suatu perubahan pada satu elemen kepada elemen lain. Pada bisnis model ini elemen yang coba ditambah adalah key activity dari divisi marketing, penambahan key activity ini sendiri unntuk meningkatkan pendapatan perusahaan tanpa terlalu banyak menambah biaya.

\section{Analisis SWOT Setiap Elemen Model Bisnis Kanvas}

Setelah membuat model bisnis awal PT XYZ, kemudian penulis membuat penjabaran SWOT dengan pendekatan empat bidang utama dalam suatu bisnis, yaitu pelanggan, penawaran, infrastruktur, dan kelangsungan finansial. Model bisnis sendiri ibarat cetak biru sebuah strategi yang diterapkan melalui struktur organisasi, proses dan sistem. Analaisis SWOT mengarahkan analisisi strategi dengan fokus pada kekuatan (strength), kelemahan (weaknesses), peluang (opportunity), dan ancaman (threats) yang merupakan hal kritis bagi keberhasilan perusahaan. Pengenalan akan kekuatan yang dimiliki akan membantu perusahaan untuk tetap menaruh perhatian dan melihat peluang-peluang baru. Sementara penilaian yang jujur terhadap kelemahankelemahan yang ada akan memeberikan bobot realistis pada rencana-yang akan dibuat perusahaan.

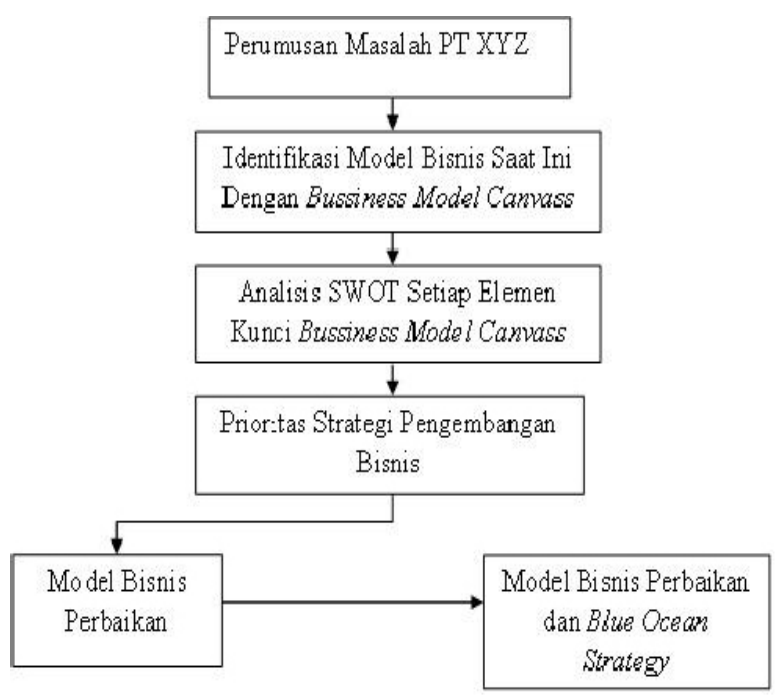

Gambar 2. Kerangka pemikiran penelitian 


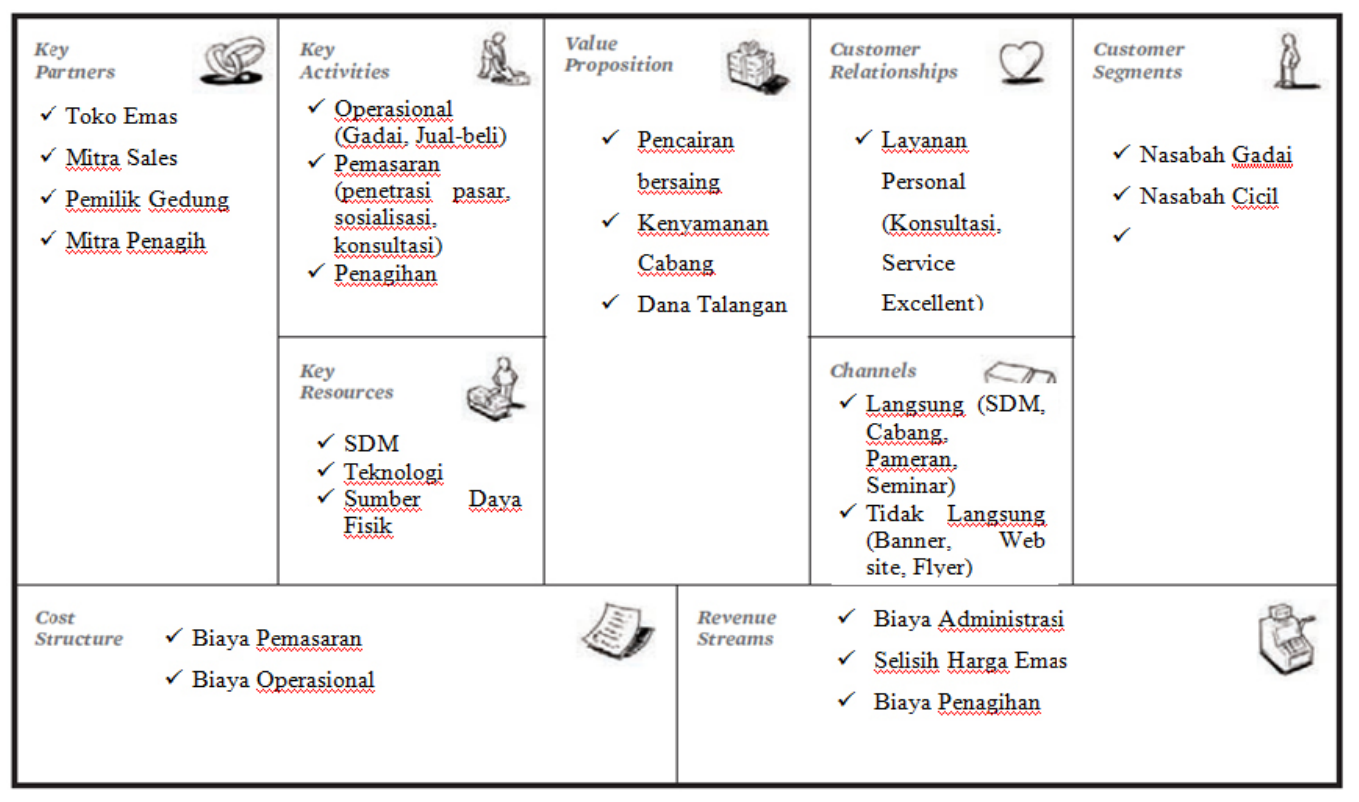

Gambar 3. Model bisnis kanvas saat ini

Penulis kemudian melakukan pemetaan model bisnis kanvas berdasarkan analisi kekuatan, kelemahan, peluang dan ancamannya. Hasil analisis SWOT elemenelemen model bisnis kanvas PT XYZ, kemudian dirangkum pada Tabel 2. Tujuan pengembangan pada layanan gadai dan pembiayaan bertujuan membangun bisnis berakar kuat yang terbentuk dari banyaknya transaksi retail, pengembangan ini diharapkan dapat membantu pengelolaan emas yang dimiliki oleh masyarakat menengah kebawah. Dari hasil diskusi kemudian penulis merumuskan kembali elemen apa saja yang dapat di dilakukan perubahan dari model bisnis kanvas yang dijelaskan dalam Gambar 4. Rencana perbaikan model bisnis PT XYZ merupakan perbaikan dari model bisnis yang sudah berjalan saat ini, perubahan dititik beratkan kepada beberapa perubahan diantaranya:

1. Revenue stream, perlu adanya pengkajian kembali arus pendapatan terutama pada tarif biaya titip agar dapat bersaing dengan biaya titip kompetitor. Sebagai salah satu contoh untuk produk empat bulan, Pegadaian mengenakan biaya sebesar $10,2 \%$ sementara PT XYZ mengenakan biaya hingga 14,6\%. Dengan kelebihan Pegadaian yang memiliki cabang yang lebih tersebar maka PT XYZ dapat memberikan penawaran yang lebih baik bagi nasabah agar lebih memilih PT XYZ sebagai alternatif transaksi.
2. Coststructure, pengkajian arus biaya perlu dilakukan untuk memastikan efisiensi pengeluaran biaya agar penggunaannya tepat sasaran. Salah satu contoh seperti pemberian hadiah dan bonus disesuaikan dengan pendapatan real perusahaan. Selanjutnya, perlu adanya penambahan pos.

3. Key activity, penambahan aktivitas kunci salah satunya adalah pelatihan dan kontrol kualitas sumber daya manusia. Perbaikan elemen ini diharapkan meningkatkan kualitas karyawan sehingga lebih menguasai tanggung jawab kerja yang di emban. Dengan pencapaian target yang baik, tingkat turn over karyawan khususnya sales diharapkan dapat ditekan.

Perbedaan warna dalam kolom setiap elemen menggambarkan poin-poin yang perlu ditambahkan dan di tingkatkan (Gambar 5). Pembuatan model bisnis alternatif ini disesuaikan dengan kondisi normal perusahaan dimana posisi bisnis model perbaikan sebelumnya telah dijalankan. Metode ini memberikan gambaran besar secara visual yang membantu untuk melihat dampak suatu perubahan pada satu elemen kepada elemen lain. Pada bisnis model ini elemen yang coba ditambah adalah key activity dari divisi marketing, penambahan key activity ini sendiri unntuk meningkatkan pendapatan perusahaan tanpa terlalu banyak menambah biaya. Tahapan perubahan seperti yang terlampir dalam Tabel 3. Hasil dari pengembangan model bisnis menggunakan BOS kemudian dituangkan kedalam model bisnis kanvas alternatif (Gambar 5). 


\begin{tabular}{|c|c|}
\hline Blok Bangunan & Kekuatan \\
\hline \multicolumn{2}{|c|}{ Penilaian hubungan pelanggan } \\
\hline $\begin{array}{l}\text { Customer } \\
\text { Segment }\end{array}$ & $\begin{array}{l}\text { - Karyawan dan Ibu rumah } \\
\text { tangga } \\
\text { - Vendor toko emas } \\
\text { - Nasabah yang memiliki } \\
\text { barang jaminan jatuh } \\
\text { tempo }\end{array}$ \\
\hline
\end{tabular}

\section{Penilaian Proposisi Nilai}

\begin{tabular}{|c|c|c|}
\hline $\begin{array}{l}\text { Value } \\
\text { Proposition }\end{array}$ & $\begin{array}{l}\text { - Sistem pembayaran cicilan } \\
\text { - Keamanan memadai } \\
\text { - Nilai Pencairan tertinggi }\end{array}$ & $\begin{array}{l}\text { - Masyarakat umumnya belum } \\
\text { terbiasa dengan sistem gadai } \\
\text { cicilan } \\
\text { - Produk kurang variatif } \\
\text { - Biaya titip lebih tinggi } \\
\text { dibanding kompetitor. }\end{array}$ \\
\hline Channel & $\begin{array}{l}\text { - Pemanfaatan dunia digital. } \\
\text { - Pameran perhiasan. }\end{array}$ & $\begin{array}{l}\text {-Penjualan via vendor tanpa } \\
\text { kontrol standar dari PT XYZ. } \\
\text { ○ Jumlah cabang PT XYZ } \\
\text { belum sebanyak kompetitor. } \\
\text { - Penjelasan brosur kurang } \\
\text { komunikatif. } \\
\text { - Rendahnya kepercayaan } \\
\text { nasabah dibandingkan } \\
\text { kepada kompetitor }\end{array}$ \\
\hline $\begin{array}{l}\text { Customer } \\
\text { Relationship }\end{array}$ & $\begin{array}{l}\text { - Pelayanan yang nyaman } \\
\text { - Konsultasi Produk } \\
\text { - Notifikasi via email, surat, } \\
\text { telepon dan SMS } \\
\text { - CSR, seminar emas dan } \\
\text { customer gathering }\end{array}$ & $\begin{array}{l}\text { - Kurang pendekatan kepada } \\
\text { nasabah retail. } \\
\text { - Komunikasi yang kurang } \\
\text { baik saat penyampaian } \\
\text { produk, sehingga ada } \\
\text { nasabah yang slah paham }\end{array}$ \\
\hline
\end{tabular}

\section{Penilaian struktur biaya}

Revenue Stream $\quad$ Margin pendapatan perusahaan yang diperoleh dari transaksi mencapai $29,5 \%$ pertahun apabila pembayaran lancar hingga penebusan.

$\begin{array}{ll}\text { Cost Structure } \quad & \text { Pemanfaatan fasilitas } \\ & \text { dunia maya yang } \\ & \text { menggunakan biaya lebih } \\ & \text { rendah untuk mendukung } \\ & \text { kinerja perusahaan. }\end{array}$

- Nasabah sensitif terhadap perubahan harga

- Segmen nasabah terbatas

- Maintenance untuk nasabah lama kurang

\author{
- Nasabah baru dari \\ segmen masyarakat \\ muda, tabungan Emas, \\ arisan emas
}

- Oknum yang berusaha memasukan barang palsu - Nasabah pindah ke perusahaan kompetitor
- Biaya titip kompetitorlebih rendah

- Penetapan biaya yang berkurangi lewat deviasi.

- adanya nasabahgagal bayar

- Perusahaan masih bergantung pada pinjaman pihak ketiga.
- Perlu pengkajian biaya yang dikeluarkan setiap departemen.
- Pemberian stimulus di awal transaksi

- Memperluas pemasaran produk pada kelompok dan jenis barang yang lebih spesifik

-Pembuatan sistem terintegrasi

- Informasi barang lelang

- Branding ditempat strategis

\footnotetext{
- Pendekatan kepada nasabah retail.

- Pendekatan terhadap nasabah yang lokasinya jauh dari cabang dengan membuat fasilitas gadai keliling.
}

- Kompetitor dengan pendanaan yang lebih baik.

- Produk memiliki masa lelang yang lebih cepat dibandingkan kompetitor - Penilaian emas sebagai barang tersier

- Fasilitas online kompetitor lebih friendly user

- Konsep ditiru kompetitor

- Kurang informasi barang take over

- Kurang tindak lanjut terhadap komplain.

- Nasabah sensitif terhadap harga

- Oknum take over

- Jumlah cabang masih terbatas.

\footnotetext{
- Biaya untuk fasilitas tambahan.

- Pendapatan dari kenaikan harga barang saat lelang.

- Penambahan biaya saat take over.
}
- Investor yang ingin menanamkan saham untuk industi gadai.
- Produk baru yang bersaing

- Kenaikan bunga pinjaman akibat naiknya suku bunga

- Turunnya Harga emas dibawah pencairan yang dilakukan saat awal transaksi.

- Biaya tak terduga diluar anggaran

- Barang jaminan yang palsu yang tidak sesuai dengan standar perusahaan.

- Biaya tak terduga dari transaksi belum di perhitungkan oleh perusahaan

\footnotetext{
- Angkatan kerja yang terus bertambah

- Pelatihan Internal

- Membuka lebih banyak cabang di tempat-tempat strategis
}

- Posisi cabang yang dekat kompetitor membuat nasabah mudah berpindah

- Kompetensi karyawan yang kurang dapat menghambat perkembangan perusahaan

- Munculnya Instansi gadai baru yang mengincar karyawan terlatih PT $\mathrm{XYZ}$ 
Tabel 2. Analisis SWOT Model Bisnis Kanvas (Lanjutan)

\begin{tabular}{|c|c|c|c|c|}
\hline Blok Bangunan & Kekuatan & Kelemahan & Peluang & Ancaman \\
\hline Key Activity & $\begin{array}{l}\text { - Pelayanan kekeluargan } \\
\text { kepada nasabah. } \\
\text { - Aktivitas SOP diatur dalam } \\
\text { SOP dan memo yang } \\
\text { dirancang dengan baik. } \\
\text { - Fleksible dalam } \\
\text { menjangkau nasabah }\end{array}$ & $\begin{array}{l}\text { - Kurang kepatuhan dengan } \\
\text { pembuatan berita acara dan } \\
\text { deviasi. } \\
\text { - Alur persetujuan yang } \\
\text { panjang } \\
\text { - Koordinasi cabang terbagi } \\
\text { menjadi } 2 \text { kepala dengan } \\
\text { kepentingan berbeda. } \\
\text { - Turn over tinggi } \\
\text { - SOP dan memo kurang } \\
\text { memiliki kekuatan. } \\
\text { - Kesalahpahaman dengan } \\
\text { instansi gadai lain }\end{array}$ & $\begin{array}{l}\text { - Pelayanan tambahan } \\
\text { yang dapat diberikan ke } \\
\text { nasabah } \\
\text { - Inovasi produk yang } \\
\text { dapat bersaing dengan } \\
\text { produk dari kompetitor. } \\
\text { - Optimalisasi pelayanan } \\
\text { via web. }\end{array}$ & $\begin{array}{l}\text { - Kompetensi tenaga } \\
\text { outsource yang kurang, } \\
\text { sehingga perlu dilatih } \\
\text { kembali agar sesuai } \\
\text { dengan kebutuhan } \\
\text { perusahaan. } \\
\text { - Adanya oknum yang } \\
\text { berusaha memasukkan } \\
\text { marang palsu ke } \\
\text { perusahaan. } \\
\text { - Perusahaan sejenis yang } \\
\text { meniru produk PT XYZ } \\
\text { dengan biaya titip yang } \\
\text { lebih murah. }\end{array}$ \\
\hline Key Partnership & $\begin{array}{l}\text { - Perusahaan bermitra } \\
\text { dengan vendor dan toko } \\
\text { emas terpercaya. } \\
\text { - Hubungan yang baik } \\
\text { dengan vendor. } \\
\text { - Tenaga outsource untuk } \\
\text { memudahkan pengelolaan } \\
\text { man power. }\end{array}$ & $\begin{array}{l}\text { - Penilaian terhadap kualitas } \\
\text { dan kuantitas barang yang } \\
\text { hanya ditentukan oleh pihak } \\
\text { vendor saja. } \\
\text { - Kualitas tenaga outsource } \\
\text { yang kadang tidak } \\
\text { sesuai dengan kebutuhan } \\
\text { perusahaan. }\end{array}$ & $\begin{array}{l}\text { - Jaringan vendor yang } \\
\text { masih terbuka luas di } \\
\text { berbagai wilayah. } \\
\text { - Kerja sama dengan } \\
\text { berbagai kelompok } \\
\text { masyarakat dan } \\
\text { perusahaan. } \\
\text { - Vendor baru }\end{array}$ & $\begin{array}{l}\text { - Oknum vendor dan toko } \\
\text { emas yang memasukkan } \\
\text { barang palsu. } \\
\text { - Oknum tenaga outsource } \\
\text { berkerja sama dengan } \\
\text { instansi gadai lain untuk } \\
\text { memasukan barang yang } \\
\text { tidak sesuai standar. } \\
\text { - Tenaga Outsource yang } \\
\text { kurang kompeten }\end{array}$ \\
\hline
\end{tabular}

\begin{tabular}{|c|c|c|c|c|}
\hline \multirow{3}{*}{$\begin{array}{l}\text { Key } \\
\text { Partners } \\
\checkmark \text { Toko Emas } \\
\checkmark \text { Mitra Sales } \\
\checkmark \text { Pemilik Gedung } \\
\checkmark \text { Mitra Penagih }\end{array}$} & $\begin{array}{l}\text { Key } \\
\text { Activities }\end{array}$ & \multirow{3}{*}{$\begin{array}{l}\text { Value } \\
\text { Proposition } \\
\checkmark \text { Pencairan } \\
\text { bersaing } \\
\checkmark \text { Kenvamanan } \\
\quad \text { Cabang } \\
\checkmark \text { Dana Talangan } \\
\checkmark \text { Take Over } \\
\checkmark \text { Konsultasi }\end{array}$} & $\begin{array}{l}\text { Customer } \\
\text { Relationships }\end{array}$ & \multirow{3}{*}{$\begin{array}{l}\text { Customer } \\
\text { Segments } \\
\checkmark \text { Nasabah Gadai } \\
\checkmark \text { Nasabah Cicil } \\
\checkmark \text { Nasabah Take Over }\end{array}$} \\
\hline & $\begin{array}{l}\checkmark \text { Operasional (Gadai, } \\
\text { Jual-beli) } \\
\checkmark \text { Pemasaran } \\
\text { (penetrasi } \\
\text { sosialisasi, pasar, } \\
\text { konsultasi) } \\
\checkmark \text { Penagiham } \\
\checkmark \text { Regulasi kebijakan }\end{array}$ & & $\begin{array}{l}\checkmark \text { Layanan Personal } \\
\checkmark \text { Komunitas Emas }\end{array}$ & \\
\hline & $\begin{array}{l}\text { Key } \\
\text { Resources } \\
\checkmark \text { SDM } \\
\checkmark \text { Teknologi } \\
\checkmark \text { Sumber Daya Fisik } \\
\checkmark \text { Training Centre }\end{array}$ & & $\begin{array}{l}\text { Channels } \\
\checkmark \text { Langsung (SDM, } \\
\text { Cabang, Pameran, } \\
\text { Seminar) } \\
\checkmark \text { Tidak Langsung } \\
\text { (Banner, Web site, } \\
\begin{array}{l}\text { Flyer, Mouth to } \\
\text { mouth) }\end{array}\end{array}$ & \\
\hline $\begin{array}{ll}\text { Cost } & \checkmark \text { Pengkajiar } \\
\text { Structure } & \checkmark \text { Pengkajiar } \\
& \checkmark \text { mar }\end{array}$ & $\begin{array}{l}\text { a Biaya Pemasaran } \\
\text { n Biaya Operasional }\end{array}$ & $\begin{array}{l}\text { Revenue } \\
\text { Streams }\end{array}$ & $\begin{array}{l}\checkmark \text { Biaya Administrasi } \\
\checkmark \text { Selisih Harga Emas } \\
\checkmark \text { Biaya Penagihan } \\
\checkmark \text { Biaya Titip Bersaing }\end{array}$ & \\
\hline
\end{tabular}

Gambar 4. Model bisnis kanvas perbaikan 


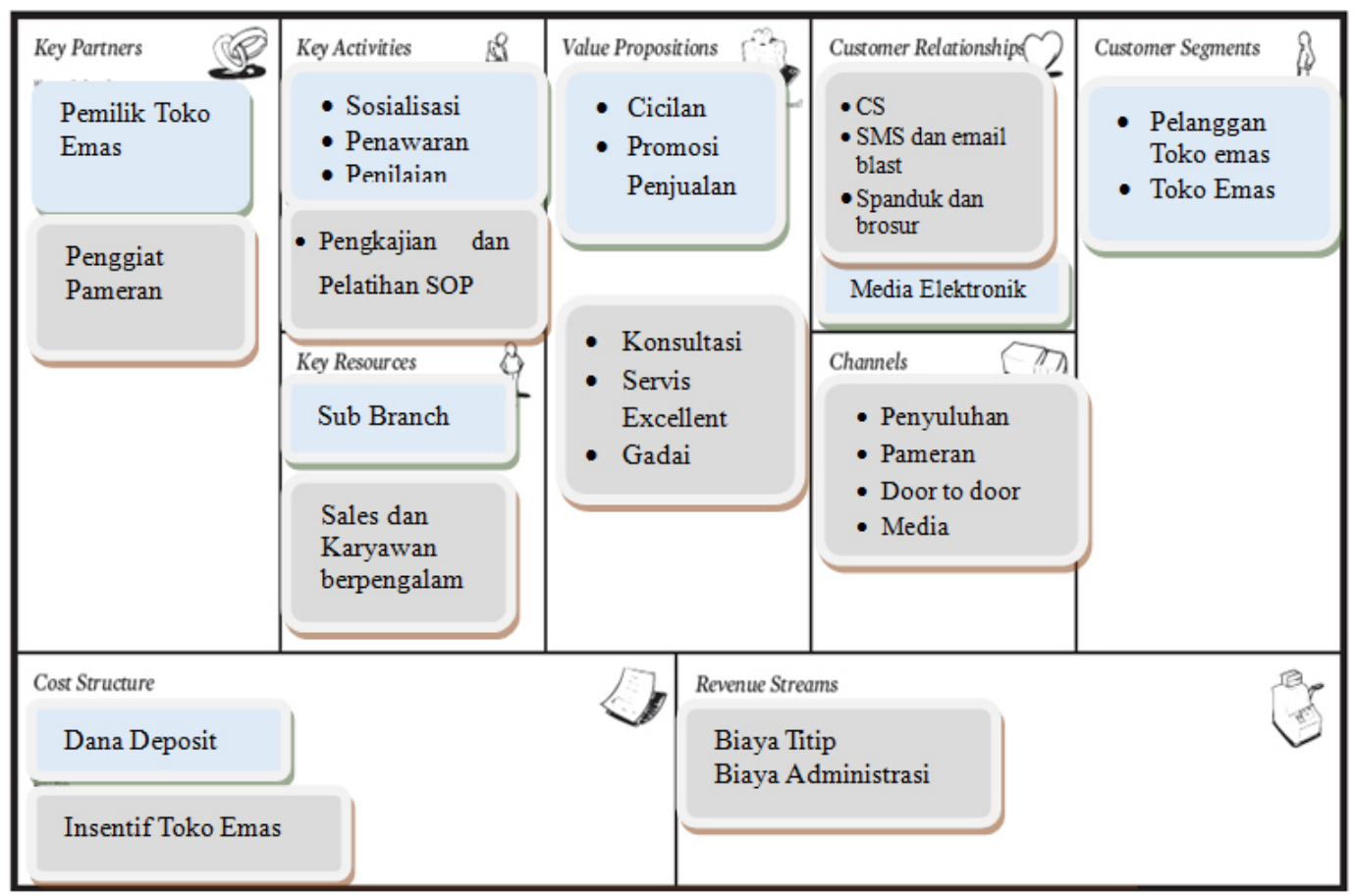

Gambar 5. Blue ocean strategy PT XYZ

Tabel 3. Blue ocean strategy dalam model bisnis alternatif

\begin{tabular}{|c|c|c|}
\hline Tata Bangunan & Menciptakan & Menambahkan \\
\hline Customer Segment & $\begin{array}{l}\text { Pelanggan toko emas } \\
\text { Toko emas }\end{array}$ & \\
\hline Key Resouces & Sub branch di pasar & Sales dan karyawan terlatih \\
\hline Key Activity & $\begin{array}{l}\text { Sosialisasi program ke toko emas } \\
\text { Penawaran produk kepada calon nasabah } \\
\text { Penilaian toko emas }\end{array}$ & Pembuatan dan pelatihan SOP \\
\hline Value Proposition & $\begin{array}{l}\text { Fasilitas pembelian cicilan } \\
\text { Promosi penjualan }\end{array}$ & $\begin{array}{l}\text { Konsultasi sebelum pembelian } \\
\text { Pelayanan yang cepat dan nyaman } \\
\text { Pelayanan gadai }\end{array}$ \\
\hline Channel & $\begin{array}{l}\text { Mencantumkan toko emas yang bekerjasama } \\
\text { dengan PT XYZ dalam kegiatan promosi }\end{array}$ & Mendatangi toko satu persatu \\
\hline & & $\begin{array}{l}\text { Pemasaran media elektronik dan cetak } \\
\text { Kerja sama di berbagssi instansi } \\
\text { Pameran }\end{array}$ \\
\hline Customer Relationship & - & $\begin{array}{l}\text { CS untuk penjelasan produk } \\
\text { SMS dan email untuk nasabah } \\
\text { Spanduk, poster, flyer }\end{array}$ \\
\hline Key PartnerShip & Pemilik toko emas & Penggiat pameran Perhiasan \\
\hline Cost Structure & Dana deposit & Insentif \\
\hline Revenue Stream & - & $\begin{array}{l}\text { Biaya titip } \\
\text { Biaya administrasi }\end{array}$ \\
\hline
\end{tabular}

\section{Customer Segment}

1. Pelanggan toko emas yang ingin memiliki perhiasan dengan cara mencicil.

2. Toko emas, akan mendapat dana sebagai deposit yang diberikan sesuai dengan kebutuhan transaksi.
Dana akan dipotong setiap kali ada nasabah yang melakukan pembelian melalui cicilan PT XYZ.

3. Komunitas, nasabah yang terdapat dalam komunitas dan tertarik memiliki emas dapat saling bertukar informasi mengenai emas. 


\section{Key Resouce}

1. Sales dan karyawan berpengalaman, bertugas memfasilitasi transaksi yang dilakukan di toko emas. Fasilitasi yang dilakukan mulai dari pendampingan dan konsultasi saat pemilihan barang, proses transaksi, pencatatan manual transaksi hingga rekap penggunaan dana deposit pada akhir hari.

2. Subbranch di dalam pasar, berfungsi sebagai tempat dimana transaksi diproses secara sistem, tempat penyimpanan barang sementara sebelum di pindahkan ke cabang utama, sekaligus tempat nasabah melakukan konsultasi sebelum melakukan pembelian emas.

\section{Key Activity}

1. Sosialisasi kepada pemilik toko emas, berupa undangan gathering untuk menjelaskan manfaat dari program cicilan sekaligus peraturan yang perlu dijalankan sebagai kontrol dari kedua belah pihak.

2. Menawarkan kepada pelanggan toko emas untuk melakukan pembelian perhiasan di toko emas melalui cicilan di PT XYZ, kelebihan yang didapatkan, nasabah dapat melakukan pembelian tanpa dipengaruhi fluktuasi harga, nasabah dapat melakukan upgrade barang yang di inginkan dengan fasilitas cicilan.

3. Pembuatan SOP termasuk didalamnya proses transaksi, syarat dan ketentuan sebagai pedoman proses transaksi yang wajib dilakukan kedua belah pihak.

4. Penilaian Toko Emas, PT XYZ melakukan pengamatan terhadap beberapa toko emas yang berada dalam satu wilayah, kemudian melakukan pendekatan dengan menjelaskan tujuan dari kerjasama antara toko emas dan PT XYZ.

\section{Value Proposition}

1. Kepada calon nasabah, memberikan fasilitas cicilan sehingga nasabah lebih leluasa memilih perhiasan yang diinginkan tanpa dibatasi oleh dana yang dimiliki.

2. Kepada calon nasabah, memberikan konsultasi produk dan perhiasan yang di inginkan sesuai dengan keinginan dan kemampuan nasabah.
3. Kepada toko emas, promosi produk akan memberikan kesempatan penjualan dengan nominal yang lebih besar dan keuntungan finansial.

4. Pelayanan Jual dan gadai, perjanjian yang dilakukan antara PT XYZ dan toko emas salah satunya untuk menjamin nasabah dapat menjual kembali barang jaminannya dengan harga yang sesuai standar pasar. Selama kelengkapan surat dan barang masih sesuai, PT XYZ akan memfasilitasi penjualan tersebut.

\section{Channel}

1. Mendatangi toko emas satu persatu untuk menawarkan program cicilan perhiasan melalui PT XYZ.

2. Meningkatkan pemasaran melalui media cetak dan media elektronik secara aktif, seperti memperluas lingkup media sosial, tampilan web dan brosur yang informatif.

3. Aktif dalam kegiatan penyuluhan komunikatif diberbagai instansi pemerintah, swasta dan komunitas, terutama didaerah sekitar toko emas.

4. Mencantumkan informasi mengenai toko emas yang bekerja sama dalam program cicilan ini.

5. Aktif mengikuti pameran perhiasan emas yang diadakan komunitas maupun pemerintah, untuk mensosialisasikan produk cicilan perhiasan emas.

6. Fasilitas penjualan kepada toko emas agar dapat dikenal luas sebagai salah satu toko emas yang bekerja sama dengan PT XYZ, salah satunya dengan mencantumkan nama toko emas pada media pemasaran yang dimiliki PT XYZ sepeti brosur, spanduk, website dan komunitas.

\section{Customer Relationship}

1. Sosialisi info mengenai produk disebarluaskan melalui SMS dan e-mail kepada nasabah yang terdapat dalam database pelanggan.

2. Customer service (CS) untuk penjelasan produk maupun saran dan keluhan.

\section{Key Partnership}

1. Pemilik toko emas, yang memberikan izin agar program ini dapat dijalankan di toko emas yang bersangkutan.

2. Event organizer (EO) yang mengadakan pameran perhiasan. 


\section{Cost Structure}

1. Dana deposit, PT XYZ dalam hal ini memberikan modal dana talangan dengan jumlah dan tenor pengisian kembali yang disesuaikan dengan kemampuan penjualan toko emas. PT XYZ akan melakukan pembayaran secara tunai untuk setiap barang jaminan yang dicicil melalui PT XYZ, dengan sistem cicilan.

2. Sebagai daya tarik untuk toko emas, PT XYZ perlu membuat skema hadiah maupun insentif untuk toko emas yang berhasil melakukan penjualan hingga tiering tertentu.

\section{Revenue Stream}

1. Biaya titip kompetitif yang dibayarkan dari cicilan pelanggan.

2. Keuntungan penjualan langsung baik dari lelang maupun barang distributor.

\section{Implikasi Manajerial}

Model bisnis perbaikan dan model bisnis yang disusun dalam penelitian ini dibuat berdasarkan diskusi dengan personil di cabang dan beberapa manager dari berbagai divisi dan jabatan berdasarkan penilaian dari kondisi internal dan eksternal perusahaan. Bisnis yang dijalankan oleh perusahaan, merupakan bidang bisnis yang sedang berkembang dengan pesat, sehingga perusahaan tidak dapat menghindari adanya kompetisi maupun peniruan ide. Hasil penelitian menunjukkan turunnya omset dari produk gadai dan pembelian unggulan antaralain disebabkan adanya penawaran kompetitor yang lebih baik, tingginya turn over sales, kurangnya kualitas dan loyalitas karyawan serta regulasi yang belum mendukung key activity perusahaan.

PT XYZ perlu memperbaiki beberapa elemen yang ditunjukan dalam model bisnis kanvas perbaikan, terutama untuk peningkatan kualitas dan kapasitas key resources melalui pelatihan karyawan secara bertahap dan terjadwal sehingga kedepannya perusahaan dapat lebih fokus pada pengembangan strategi perusahaan daripada fokus rekruitmen dikarenakan turn over yang tinggi, pentingnya kedisiplinan dan konsistensi dalam membuat peraturan, produk dan kebijakan yang berlaku perlu disadari oleh karyawan dan manajemen. Perusahaan juga perlu melakukan pengkajian kembali terhadap kemasan produk, pemberian gimmick dan pelayanan aftersales yang lebih menarik agar dapat lebih diterima oleh calon nasabah.

Pengembangan perusahaan berikutnya selain melalui penambahan cabang, perusahaan juga perlu mengoptimalkan kerjasama dengan kompetitor untuk mendekati pangsa pasar yang berbeda sehingga dapat meningkatkan brand image dan pendapatan perusahaan. Pemasaran melalui internet marketing juga perlu dikembangkan, menimbang pesatnya perkembangan ilmu teknologi, pemasaran melalui internet dapat menjadi salah satu promosi dengan biaya terjangkau.

\section{KESIMPULAN DAN SARAN}

\section{Kesimpulan}

Hasil identifikasi kondisi perusahaan awal menggambarkan kondisi perusahaan saat ini, dimana adanya persaingan inovasi dari kompetitor, tingginya turn over sales serta strategi pemasaran yang kurang tepat sasaran membuat adanya penurunan pendapatan dari produk unggulannya berupa gadai dan pembelian emas secara cicilan.

Hasil pengamatan Analisis SWOT perusahaan menghasilkan model bisnis perbaikan, terdapat beberapa eleman seperti key activities, cost strurcture dan key resources dalam model bisnis kanvas yang perlu dilakukan pengkajian kembali agar perusahaan dapat bersaing dengan kompetitor. Blue ocean strategy menghasilkan peluang baru bagi PT XYZ dengan menjadi penyedia dana talangan bagi nasabah untuk melakukan pembelian di toko emas yang telah bermitra dengan PT XYZ.

\section{Saran}

Penelitian ini dilakukan secara deskriptif dengan adanya keterbatasan informasi, data dan lingkup dari perusahaan, diharapkan kedepannya terdapat penelitian lanjutan dapat dilakukan dengan melibatkan informasi yang lebih terbuka dan oarang-orang dengan jabatan yang lebih tinggi sehingga penelitian lanjutan dapat memberi dampak yang lebih besar kepada perusahaan.

PT XYZ perlu terus berinovasi menciptakan programprogram menarik agar dapat memperluas pangsa pasarnya. Hal ini sebagai tindakan perventif dari 
ancaman yang muncul dari kompetitor seperti Pegadaian, Bank syariah dan sebagainya.Selain itu, lokasi cabang PT XYZ yang tersebar di area yang berbeda memiliki karakteristik pasar dan nasabah yang berbeda juga. PT XYZ perlu melakukan penyesuaian strategi terhadap kebutuhan pasar disetiap area juga perlu dikaji kembali sehingga perusahaan dapat menggunakan strategi yang tepat sasaran

\section{DAFTAR PUSTAKA}

David F. 2002. Konsep Manajemen Strategik. Edisi Bahasa Indonesia. Alih Bahasa Oleh Alexasander Sindoro. Jakarta: PT Prenhallindo.

Destiani DP.2014. Analisis Strategik model bisnis Kanvas pada PT Angkasa Pura II untuk Bandara Soekarno Hatta[Tesis]. Bogor: Instititut Pertanian Bogor.

Eppler MJ, Hoffmann F, Bresciani S. 2011. New bussiness model trought collaborative idea generation.International journal of innovation management 15(6):1323-1341. https://doi. org/10.1142/S1363919611003751.
Ghaffari MA. 2014.Pengembangan Model Bisnis Momomilk: Studi Kasus Kafe Momomilk Bogor [Tesis]. Bogor: Institut Pertanian Bogor.

Graviola T, Artem A, Yanson A. 2014. A modern notation of bussines models: a visual trend. Foresight Russia 8(2):56-70.

Leschke J. 2013. Business model mapping: a new to encourage entrepreneurial activity and accelerate new venture creation. Journal of Marketing Development and Competitiveness 7(1): 18-26

Nazir M. 1999. Metode Penelitian. Cetakan Ketiga. Jakarta: Ghalia.

Marahakim S, Wadenbori H. 2012. Bussiness model generation of Majalah Epik. Journal of Bussiness and Management 1(5):365-369.

Osterwalder A, Pigneur Y. 2012. Bussines Model Generation (terjemahan). Jakarta: PT Elex media Komputindo.

Wheelen TL, Hunger JD. 2003. Management StrategisEdisi ke dua. Yogyakarta:Penerbit Andi. 